\title{
Pressure Fluctuations as a Diagnostic Tool for Fluidized Beds
}

\author{
Technical Progress Report for the Period \\ April 1, 1995 - June 30, 1995 \\ Principal Investigator: Robert C. Brown \\ Research Assistant: Ethan Brue \\ Iowa State University \\ Ames, IA 50011
}

\begin{abstract}
Work Performed Under Grant
No. DE-FG22-94PC94210
\end{abstract}

Date Transmitted: July 14, 1995

Prepared for: U.S. Department of Energy

Pittsburgh Energy Technology Center

Pittsburgh, PA

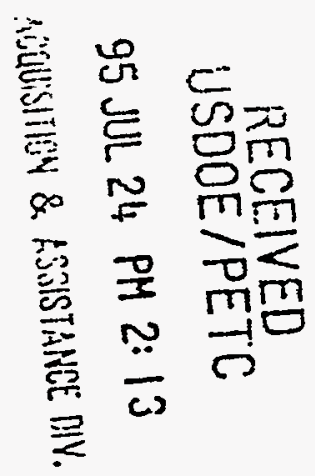




\title{
Pressure Fluctuations as a Diagnostic Tool for Fluidized Beds
}

\author{
Technical Progress Report for the Period \\ April 1, 1995 - June 30, 1995 \\ Principal Investigator: Robert C. Brown \\ Research Assistant: Ethan Brue \\ Iowa State University \\ Ames, IA 50011
}

\begin{abstract}
The first phase of experimentation for the comprehensive similitude study on the two laboratory scale cold-model circulating fluidized beds has been completed. This first phase required the acquisition and analysis of pressure fluctuation data from a 2.0 inch diameter pressurized circulating fluidized bed. The second phase required the matching of each of the 20 experiments in a cold-model twice the size of the smaller 2.0 inch circulating fluidized bed model using similitude relations. Problems of excessive electrostatic buildup were encountered in this second phase. To alleviate these problems, the large model had to be redesigned and reconstructed. The focus of the research this past quarter has been devoted to these modifications. Currently, the new sections have been constructed and the modified circulating fluidized bed is in the process of reassembly.
\end{abstract}

Two related projects were undertaken while the large circulating fluidized bed model was being modified. A bubbling bed was constructed such that pressure fluctuation data could be measured in both bubbling and turbulent fluidization regimes. The purpose of such tests was to relate pressure fluctuation structure in the lower sections of the circulating fluidized bed with phenomena observed in bubbling/turbulent regimes.

Two probes designed to measure heat transfer coefficients in the large and small circulating fluidized bed models were completed and initially tested under bubbling bed conditions. These tests insured the validity and accuracy of the bed to surface heat transfer coefficient measurement. The two probes were constructed as an additional means of validating similitude relations in circulating fluidized beds in addition to pressure fluctuations.

An abstract discussing the current results of this CFB pressure fluctuation study has been submitted to the Fifth World Congress of Chemical Engineering, an international conference to be held in San Diego, July 14-18, 1996. The paper is entitled "Validation of hydrodynamic similitude in fluidized beds via pressure fluctuations." 


\title{
Pressure Fluctuations as a Diagnostic Tool for Fluidized Beds Robert C. Brown and Ethan Brue
}

\author{
Objective
}

The purpose of this project is to investigate the origin of pressure fluctuations in fluidized bed systems. The study will asses the potential for using pressure fluctuations as an indicator of fluidized bed hydrodynamics in both laboratory scale cold-models and industrial scale boilers.

\section{Progress}

\section{CFB similitude experiments}

Twenty experiments were completed on the 2.0 " diameter cold-model CFB (SCFB) in the first stage of a comprehensive similitude study. These tests recorded pressure fluctuation data over a broad range of CFB operating conditions. Steel shot was fluidized with air at $28 \mathrm{psig}$, achieving superficial velocities that ranged from $2.1-4.0 \mathrm{~m} / \mathrm{s}$. Experiments were conducted with $0.1,0.15$, and $0.2 \mathrm{~mm}$ shot, and the solids flux was varied between 20 and $50 \mathrm{~kg} / \mathrm{m}^{2}$ s. Each experiment was designed such that it could be reproduced under conditions of similitude in the 4.0" diameter cold-model CFB (LCFB). In the initial LCFB similitude tests, problems of electrostatic buildup were encountered. Due to this electrostatic buildup in the predominantly Plexiglas CFB, particles did not circulate properly. The particles would periodically hold-up in the downcomer, and not progress smoothly through the solids return loop (L-valve). A small amount of Larostat powder (anti-static powder) was added to the bed to help reduce this problem. While this helped to reduce static build-up initially, much of the fine powder eventually left the bed via the gas exit over the course of the experimental run. Also, if excess Larostat was added to the CFB, particle agglomeration within the bed became a problem. The effect of electrostatic build-up is illustrated in Figure 1 which compares experiments with and without Larostat. Due to the dominant effect of electrostatic forces on bed hydrodynamics, it was felt that the only alternative was to redesign the bed out of aluminum and electrically ground the bed. This re-design would allow for the dissipation 
of electrostatic charge. The riser, cyclone, and L-valve of the large CFB were all redesigned using aluminum. These components have been constructed and are currently awaiting re-assembly.

\section{Heat transfer probe construction/testing}

Two appropriately scaled heat transfer probes were constructed and tested. The purpose of these probes was to provide a secondary means for validating the attainment of similitude conditions between the two beds that would complement pressure fluctuation measurements. The probes are designed to be suspended down the center of the bed from the top plate of the riser. The probe construction consists of a copper sheath surrounding a cylindrical heater cartridge with thermocouples embedded near the outer surface (see Figure 2). The heat transfer coefficient measurement is calculated from knowledge of the probe surface temperature, bed temperature, and the total power dissipated through the probe. Using a bubbling fluidized bed, the two heat transfer probes were tested and the results compared to published data.

\section{Bubbling bed experiments}

Bubbling bed pressure fluctuation data was gathered from a 4.0 " diameter bed and analyzed using standard spectral analysis techniques. The purpose of these tests was to compare pressure fluctuation structure in the lower sections of the LCFB with pressure fluctuations in bubbling/turbulent regimes. For three different particle sizes, experiments were completed to determine the dependence of the dominant (or natural) frequency of the bed on bed height, superficial velocity, and distributor plate configuration. The results show that the dominant frequency is primarily a function of the bed height and is only weakly dependent on the superficial velocity (see Figures $3 \& 4$ ). It was also observed that as the bed height increased, multiple frequency phenomena associated with the upper and lower regions of the bed were observed (see Figure 5). Some researchers have concluded that this dominant frequency in bubbling beds is due to the frequency of bubble formation. If this were the case, bubble frequency should be dependent on the type of distributor used to generate bubbles. Experiments were performed in which the only 
condition varied was the number of holes in the distributor plate. In all cases, changing the number of sites for bubble formation does not change the observed dominant frequency. This suggests that pressure fluctuation phenomena originates from a more global phenomena within the bed rather than local phenomena. The asymptotic slope of all bubbling bed frequency response plots are indicative of second order system behavior with a slope of $-40 \mathrm{~dB} / \mathrm{decade}$, similar to circulating fluidized bed results. The similarities (and differences) between CFB and BFB pressure fluctuation structure are shown in Figures 6 and 7. In both cases, a final $-40 \mathrm{~dB} /$ decade roll-off is seen and a broad dominant frequency at around $2 \mathrm{~Hz}(12 \mathrm{rad} / \mathrm{s})$ is observed in the Bode plots.

\section{Conclusions and Future Work}

The immediate goal of our future work is to re-assemble the redesigned LCFB and to complete the comprehensive similitude study in the cold-model CFBs. Once this has been completed more pressure fluctuation data will be acquired and analyzed at the ISU power plant CFB boiler. Similitude experiments will also be conducted with the heat transfer probes in the SCFB and LCFB.

\section{DISCLAIMER}

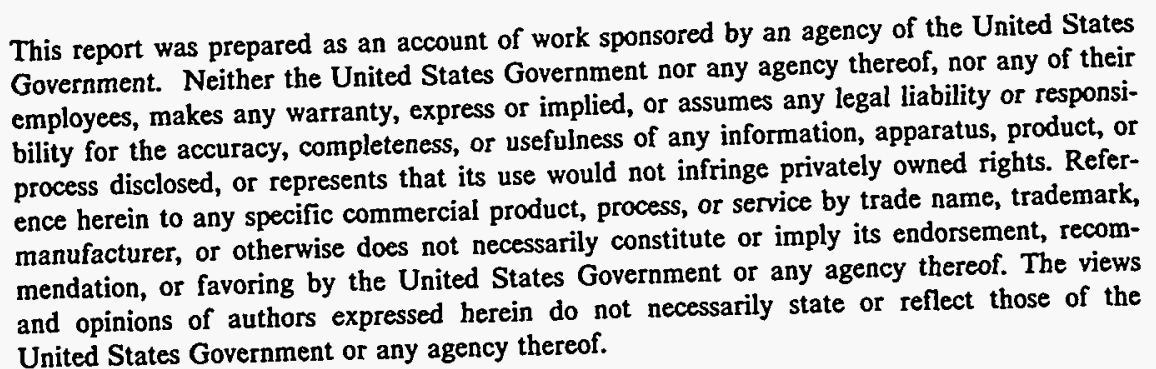


Figure 1 CFB axial voidage profiles

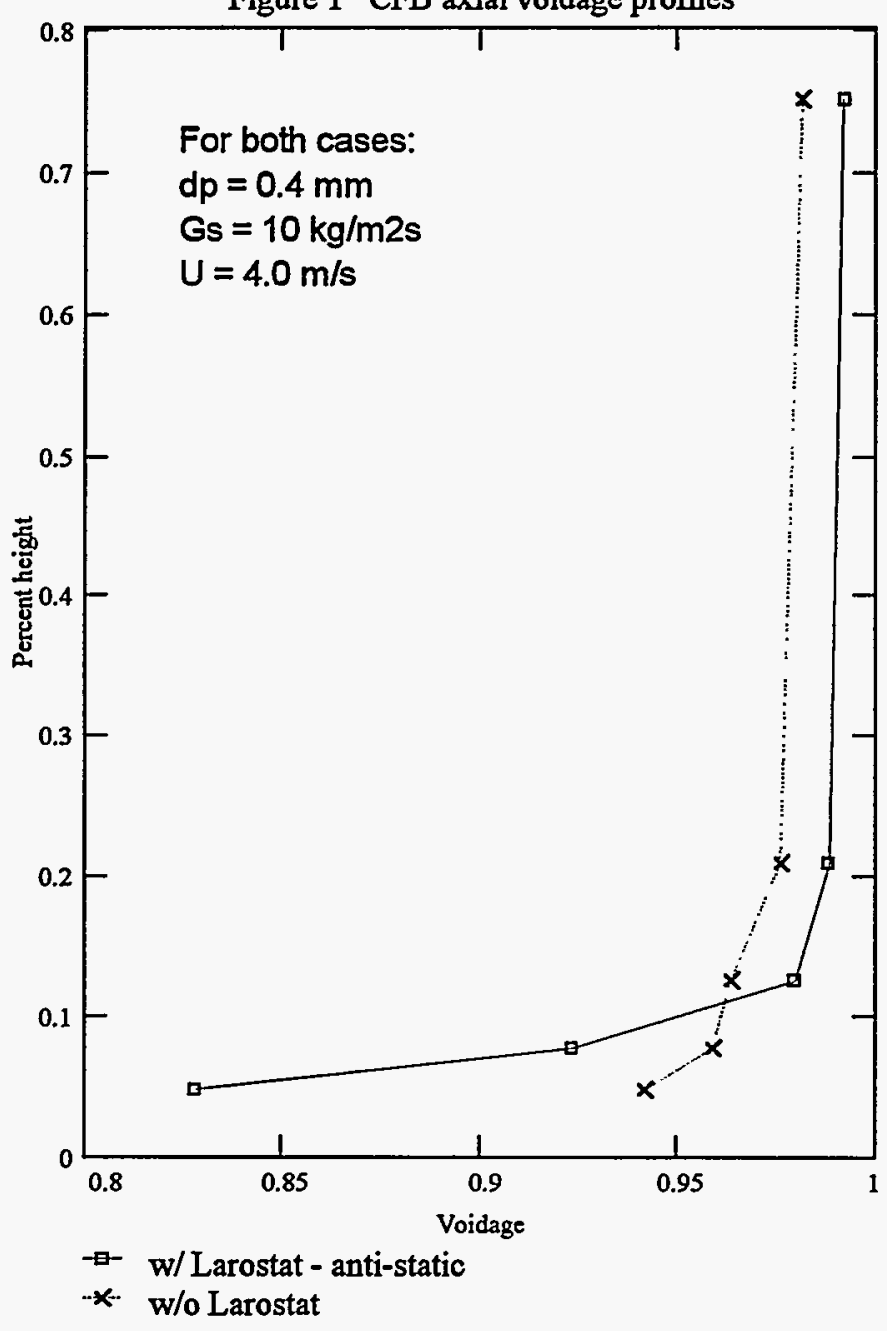


Figure 2: CFB - bed to surface heat transfer probe Dimensions are in millimeters (Large probe) Dimensions of small probe $=1 / 2$ Large probe

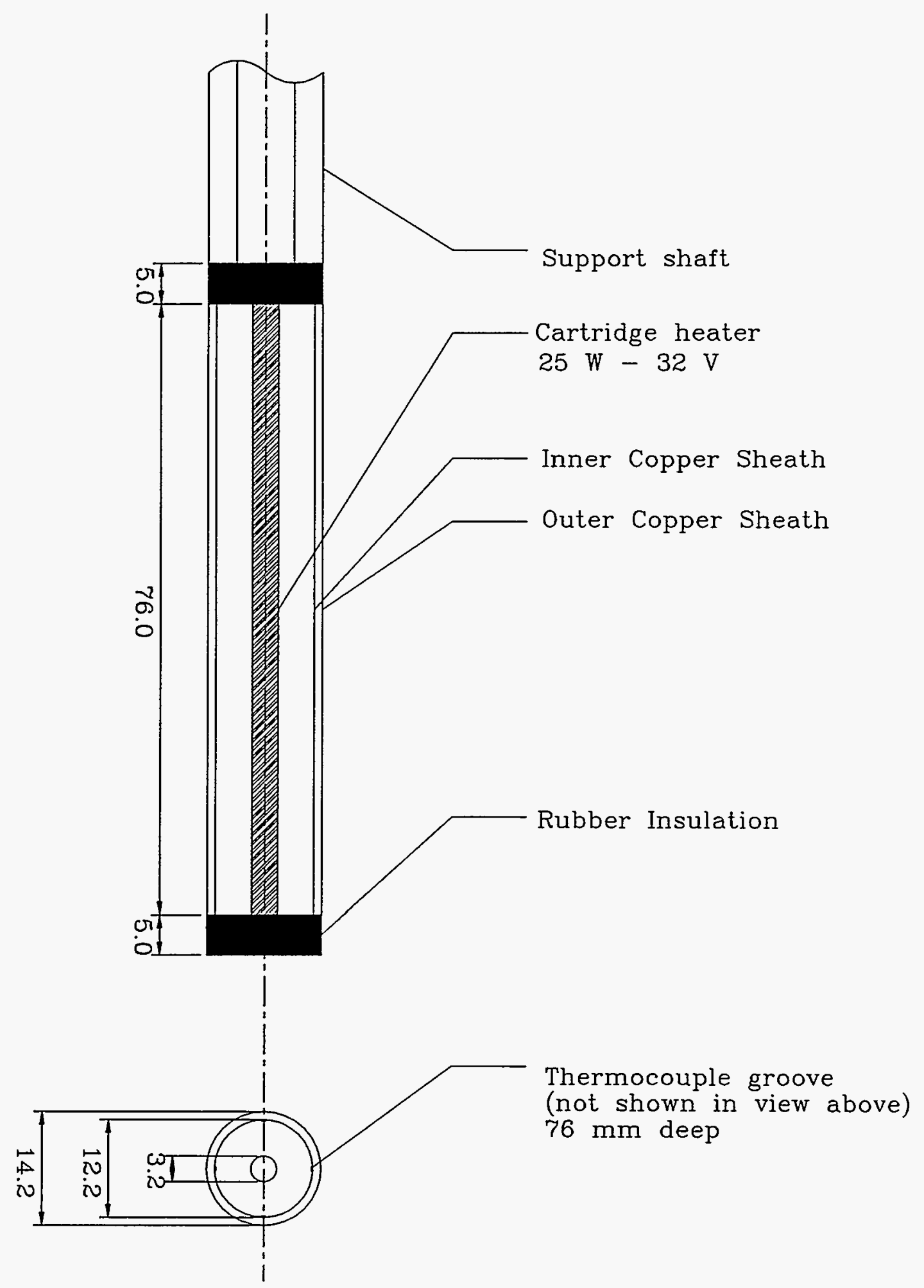


Figure 3 Dominant freq. vs. BFB height

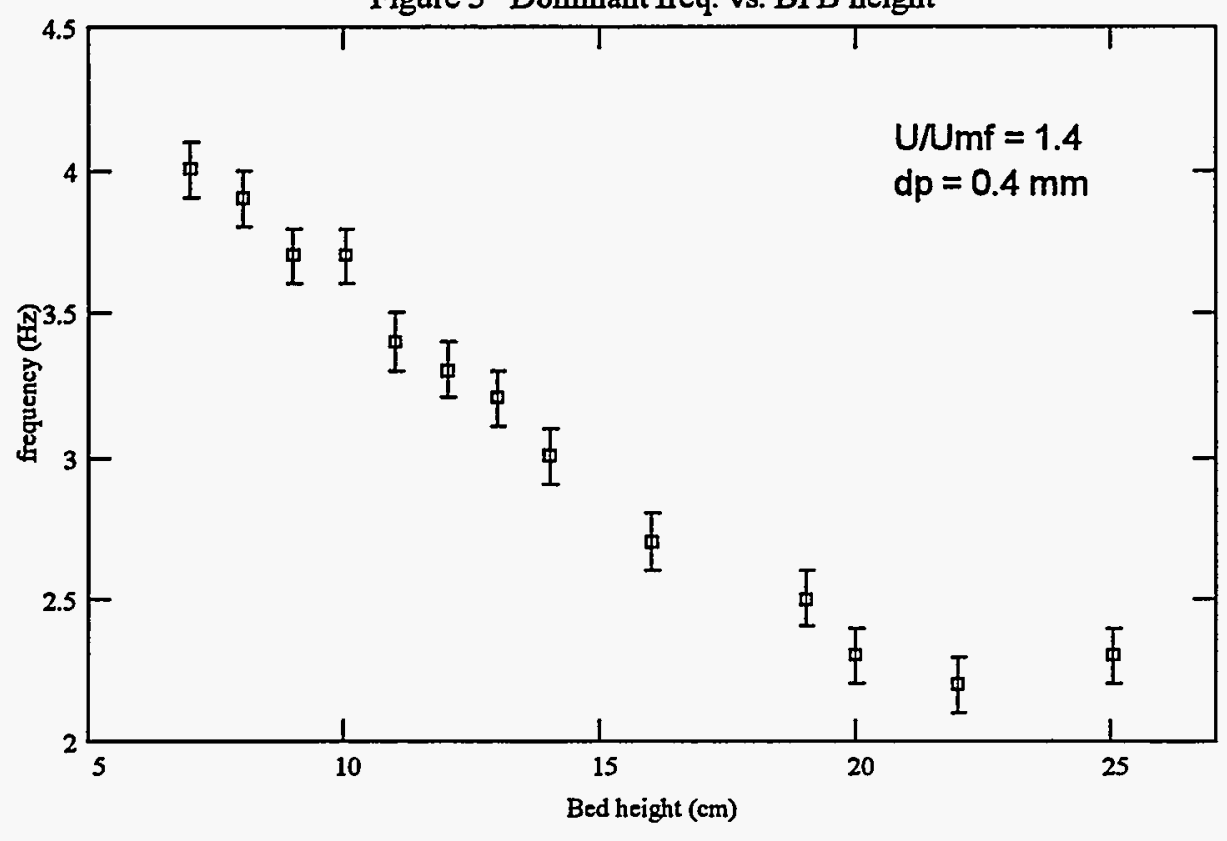

Figure 4 Dominant freq. vs. U/Umf

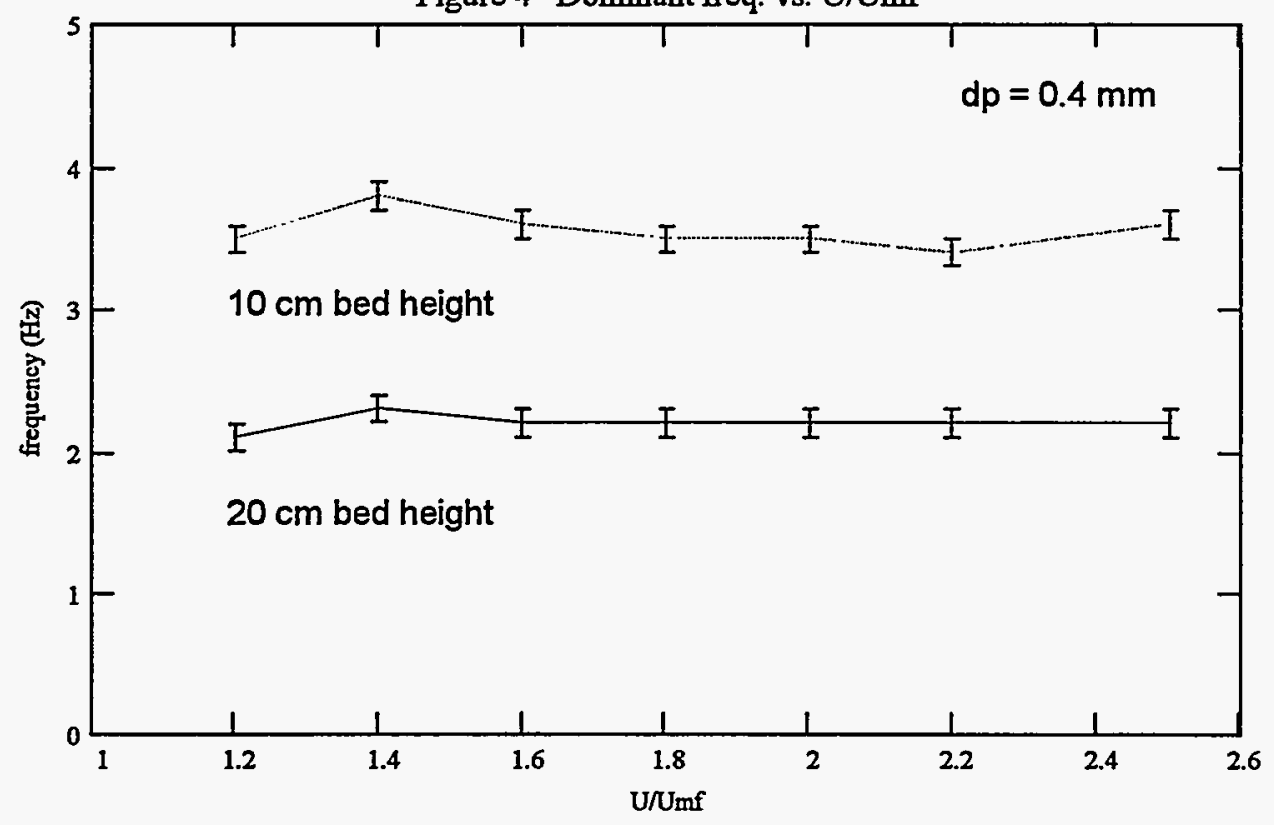


Figure 5 The Bode plot for a deep bubbling fluidized bed

bed height $=20 \mathrm{~cm}$

$\mathrm{U} / \mathrm{Umf}=1.4$

$\mathrm{dp}=0.4 \mathrm{~mm}$

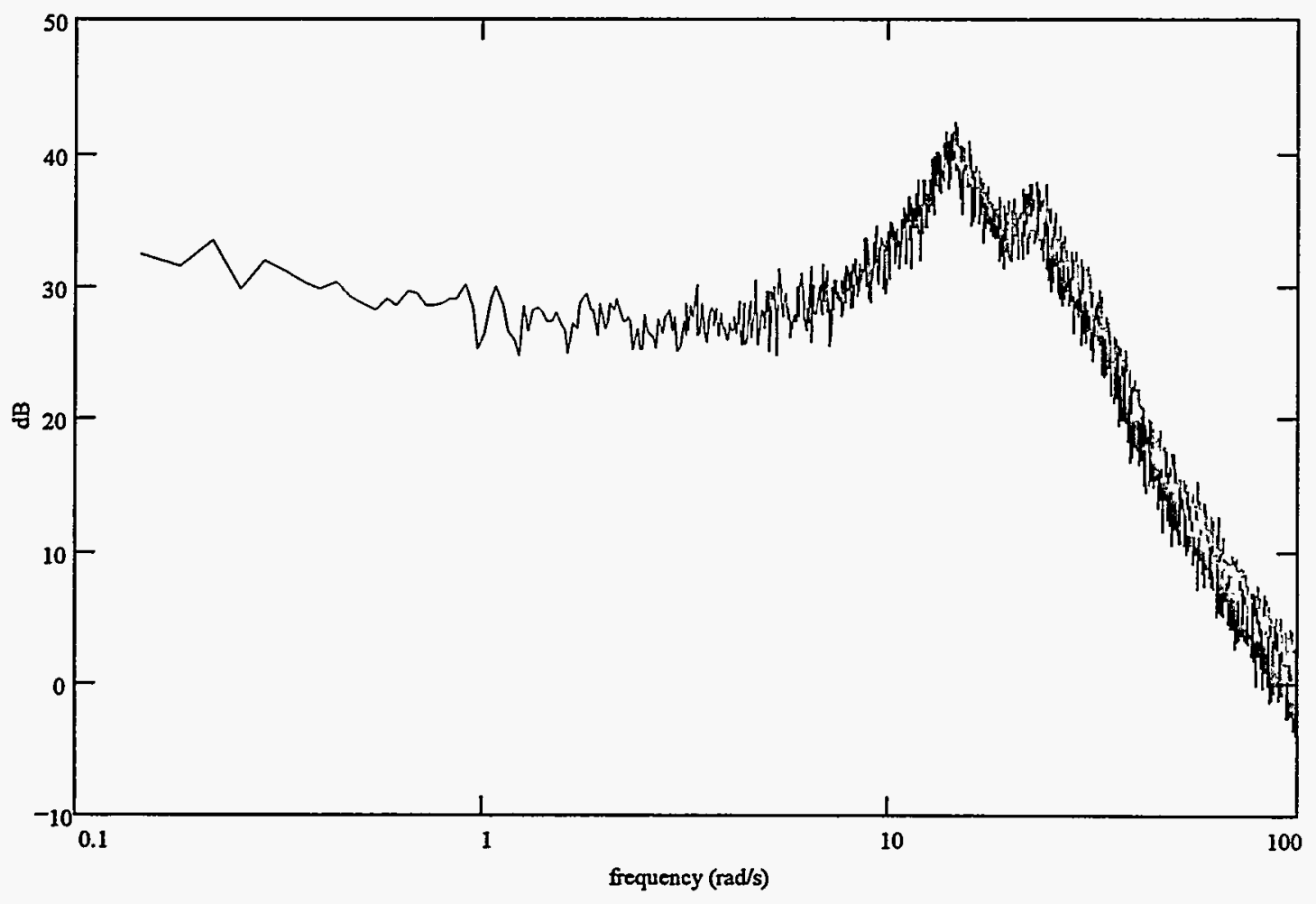


Figure 6 Bode plot of bubbling bed pressure fluctuations

(bed height $=20 \mathrm{~cm}-\mathrm{U} / \mathrm{Umf}=2.8-\mathrm{dp}=0.3 \mathrm{~mm}$ )

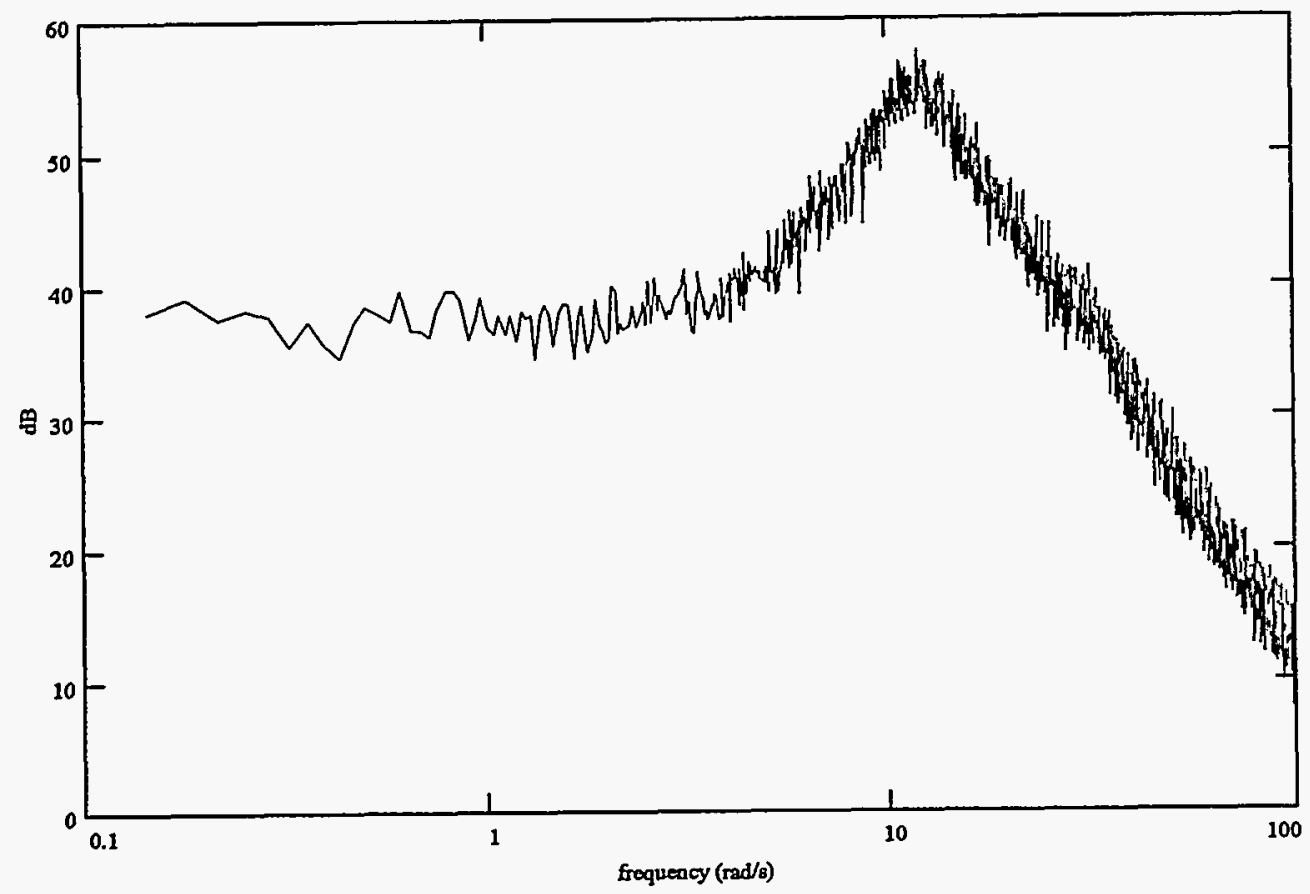

Figure 7 Bode plot of CFB pressure fluctuations in the lower dense region $\left(U=5.6 \mathrm{~m} / \mathrm{s}-\mathrm{dp}=0.3 \mathrm{~mm}-\mathrm{G}_{\mathrm{s}}=23 \mathrm{~kg} / \mathrm{m}^{2} \mathrm{~s}\right)$

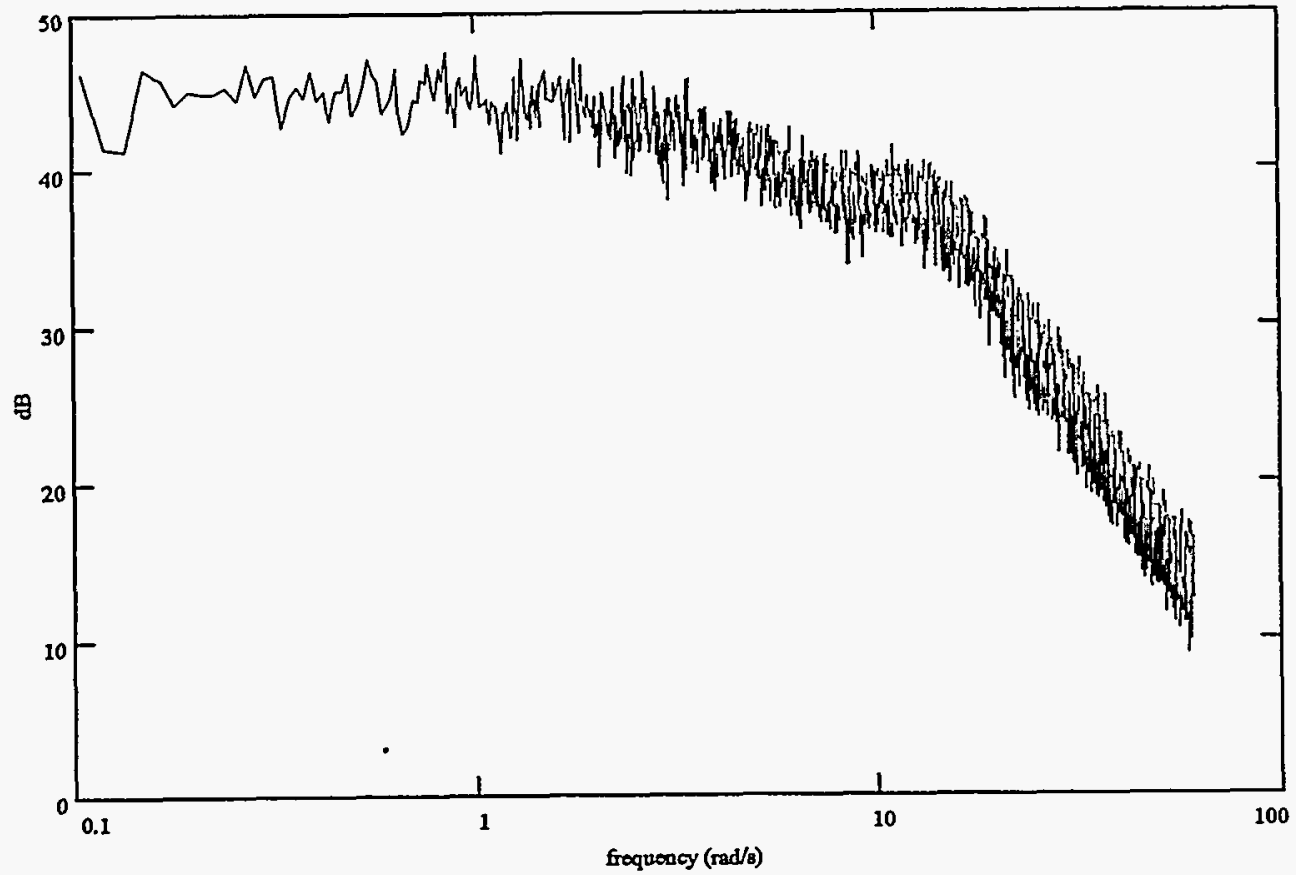

